\title{
Incidence trends and survival outcomes of penile squamous cell carcinoma: evidence from the Surveillance, Epidemiology and End Results population-based data
}

\author{
Feng Qi ${ }^{1 \#}$, Xiyi Wei ${ }^{2 \#}$, Yuxiao Zheng ${ }^{1 \#}$, Xiaohan $\operatorname{Ren}^{2}$, Xiao Li ${ }^{1}$, Erkang Zhao ${ }^{3}$ \\ ${ }^{1}$ Department of Urologic Surgery, Jiangsu Cancer Hospital \& Jiangsu Institute of Cancer Research \& Affiliated Cancer Hospital of Nanjing Medical \\ University, Nanjing, China; ${ }^{2}$ First Clinical Medical College of Nanjing Medical University, Nanjing, China; ${ }^{3}$ Department of Urology, Donghai \\ County Hospital of Traditional Chinese Medicine, Lianyungang, China \\ Contributions: (I) Conception and design: E Zhao, X Li; (II) Administrative support: X Li; (III) Provision of study materials or patients: F Qi, X \\ Wei, Y Zheng; (IV) Collection and assembly of data: F Qi, X Wei, Y Zheng, E Zhao; (V) Data analysis and interpretation: F Qi, X Ren, X Li; (VI) \\ Manuscript writing: All authors; (VII) Final approval of manuscript: All authors. \\ \#These authors contributed equally to this work. \\ Correspondence to: Xiao Li. Department of Urologic Surgery, Jiangsu Cancer Hospital \& Jiangsu Institute of Cancer Research \& Affiliated Cancer \\ Hospital of Nanjing Medical University, Nanjing 210009, China. Email: leex91@163.com; Erkang Zhao. Department of Urology, Donghai County \\ Hospital of Traditional Chinese Medicine, Lianyungang 222300, China. Email: 75886065@qq.com.
}

Background: To provide the latest incidence trends and explore survival outcomes of penile squamous cell carcinoma (PSCC) patients with or without a previous primary malignancy.

Methods: Patients diagnosed with PSCC between 1975 and 2016 in the Surveillance, Epidemiology, and End Results (SEER) database were retrospectively included. Then, we calculated the age-adjusted incidence rates (IRs) and annual percentage changes (APCs). Multivariate Cox analysis and Kaplan-Meier (KM) survival curves were conducted to investigate prognostic variables for cancer-specific survival (CSS).

Results: A total of 6,122 PSCC patients were enrolled, 1,137 of whom had a prior malignancy. The ageadjusted IR for the general population in men declined before 1987, fluctuated slightly between 1987 and 1997, and showed an upward trend after 1997, which was basically consistent with that in patients without a previous primary malignancy. The incidence trend of PSCC in the general population was similar with that in those without a previous malignancy. However, the IRs of PSCC in men with a previous malignancy have been increasing since 1975 regardless of race. Furthermore, age at diagnosis, pathological grade, extent of disease, marital status, the administration of surgery and presence of previous primary malignancy were identified to be significantly related to CSS.

Conclusions: The IRs of PSCC have been increasing in recent years. Several independent prognostic factors for CSS were identified, allowing surgeons to assess the individualized risk in advance.

Keywords: Penile squamous cell carcinoma (PSCC); Surveillance, Epidemiology, and End Results (SEER) database; incidence; prognosis

Submitted Feb 21, 2020. Accepted for publication Aug 28, 2020.

doi: 10.21037/atm-20-1802

View this article at: http://dx.doi.org/10.21037/atm-20-1802

\section{Introduction}

Penile cancer, accounting for approximately $0.3 \%$ of all male malignant tumors, is a rare urological malignant tumor. The estimated new cases and deaths of penile cancer in 2018 were 34,475 and 15,138 globally (1). The most common type of penile cancer is squamous cell carcinoma. Moreover, the incidence of penile cancer is closely related to the prevalence of human papilloma virus (HPV), which may be 
an important cause of the variation in incidence. In Uganda, penile cancer is the most common male malignancy, particularly in the uncircumcised ethnic groups $(2,3)$.

Although the pathogenesis of penile squamous cell carcinoma (PSCC) is still unclear, previous studies have found many potential risk factors, including phimosis, HPV infection, human immunodeficiency virus (HIV) infection, balanitis, excessive sexual partners, and immunodeficiency. Meanwhile, tobacco use, age and race may also be associated with the development of PSCC (4-11). In the past few decades, the prognosis of advanced penile cancer has been poor $(12,13)$. The 5 -year overall survival (OS) rates for regional and distant PSCC diseases were only 50\% and 12\% between 2009 and 2015 (https://www.cancer.org/ cancer/penile-cancer/detection-diagnosis-staging/survivalrates.html). Therefore, it is critical to investigate the risk predictors and prognostic factors for PSCC patients. Currently, most studies $(14,15)$ on PSCC are case reports or retrospective studies based on small populations due to the rarity of PSCC itself. Moreover, only few studies have been performed to evaluate the temporal incidence trends and survival outcomes of PSCC.

The Surveillance, Epidemiology and End Result (SEER) program is a large population-based database that collects cancer cases in the United States. It contains detailed information on cancer incidence, mortality and prognosis of approximately $30 \%$ of the US population. We conducted this study based on the SEER database to investigate the latest incidence trends and survival outcomes of patients with PSCC. We present the following article in accordance with the PRISMA reporting checklist (available at http:// dx.doi.org/10.21037/atm-20-1802).

\section{Methods}

\section{Database}

Original data of this study were collected from the SEER database. The SEER registry is a public registry supported by the National Cancer Institute (NCI). SEER 9 included data from nine registries in Connecticut, Hawaii, Iowa, New Mexico, Utah, Detroit (Michigan), San Francisco Oakland (California), Seattle-Puget Sound (Washington) and Atlanta (Georgia) since 1975. SEER 13 collected cancer cases diagnosed since 1992 with four additional registries [Alaska Natives, Los Angeles, San Jose-Monterey (California) and rural Georgia]. At the beginning of the 21st century, SEER 18 was developed with five new registries added (including
Greater California, Greater Georgia, Kentucky, Louisiana and New Jersey). Data agreement was signed before this study with the username of 15440-Nov2018. This study was exempt from Institutional Review Board (IRB) approval because the original data were from a public database.

\section{Patient identification}

In this study, patients diagnosed with PSCC were respectively extracted from SEER 18 using the "Case Listing Session". The inclusion criteria were as follows: (I) diagnosed as PSCC (International Classification of Diseases for Oncology: C60.0-Prepuce, C60.1-Glans penis, C60.2-Body of penis, C60.8-Overlapping lesion of penis and C60.9-Penis, NOS. Histologic Type: 80508089) with microscopical confirmation; (II) complete data were available with active follow-up; (III) type of reporting source was not autopsy only or death certificate only; (IV) cancer patients (behavior $=3$ ); (V) male sex.

Age at diagnosis was mainly categorized into $<35$, $35-49,50-64,65-79$ and $\geq 80$ years old. Primary tumor site was classified into prepuce, glans penis, body of penis, overlapping lesion of penis and not specified. Extent of disease was designated as distant, regional and localized. Race was coded as white, black, or other. The included patients were further divided into two groups based on the existence of a previous primary malignancy.

\section{Incidence rates (IRs) and annual percent changes}

We calculated the age-adjusted IRs between 1975-2016 using the "Rate Session" function (SEER 9 for 1975-1991, SEER 13 for 1992-1999, and SEER 18 for 2000-2016). A 5 -year latency was utilized in the development of temporal trend figures. Additionally, annual percent changes (APCs) were calculated to identify the trends of age-adjusted IRs in different groups.

\section{Survival outcomes}

Multivariate Cox proportional hazards regression analyses were conducted to explore independent factors which affected cancer-specific survival (CSS) significantly. Covariates of interest included age at diagnosis, presence of a previous primary cancer, race, decades of diagnosis, primary tumor site, extent of disease, pathological grade, the administration of surgery and so on. Year of diagnosis was divided into 1975-1984, 1985-1994, 1995-2004, 2005- 
2016 with 10 years as an interval. Furthermore, based on the results of multivariate Cox analyses, survival curves for different variables were produced by Kaplan-Meier (KM) analyses.

\section{Statistical methods}

Age-adjusted IRs were calculated based on the 2000 U.S. standard population using the SEER*Stat software (Version 8.3.6; www.seer.cancer.gov/seerstat). Chi-square tests were utilized to compare categorical variables. Multivariate Coxproportional hazards analyses were applied to investigate independent factors for CSS. Furthermore, survival curves for different variables were produced by KM analyses. Data were analyzed using SPSS 23.0 software (SPSS Inc, Chicago, IL, USA) and R software (Version 3.4.1). In addition, APCs were calculated using Joinpoint Regression Program (https://surveillance.cancer.gov/joinpoint/). Twosided $\mathrm{P}<0.05$ was considered to be statistically significant during the whole analysis process.

\section{Results}

A total of 6,122 patients with PSCC were identified from the SEER 18 database, 1,137 of whom had at least a prior malignancy. As shown in Table 1, those with a prior primary cancer were more likely to be older $(\mathrm{P}<0.001)$, white race $(\mathrm{P}=0.001)$, diagnosed in the last decade $(\mathrm{P}<0.001)$ and had worse differentiation $(\mathrm{P}=0.001)$. The most common site of PSCC was glans penis $(33.02 \%$ and $33.42 \%$ for patients without/with a prior primary cancer, respectively). More localized diseases were identified in patients with a prior primary cancer $(\mathrm{P}=0.033)$. However, blank or ambiguous data existed in many patients in specific variables, such as primary tumor site, pathological grade and extent of disease. After eliminating these meaningless interference data, we found that there were no significant differences in extent of disease between two groups of patients with and without a prior malignancy (details were shown in Table S1). The most important treatment type was surgery for all patients (72.50\% and $78.63 \%$ for patients without/with a prior primary cancer, respectively).

\section{IRs and annual percentage changes (APCs) in PSCC}

Tables 2-4 show the case counts and IRs for PSCC by racial group and age group. As shown in Figure 1, the age-adjusted IR declined before 1987 and fluctuated slightly between
1987 and 1997 for male population. After 1997, it showed an upward trend. For patients without a previous primary malignancy, the age-adjusted IR was basically consistent with that of the general population. However, for those with previous a previous malignancy, the overall incidence has been increasing slowly.

The incidence trend of PSCC in the general population was similar with that in those without a previous malignancy. In white individuals, the IR was basically in a steady upward trend. However, in blacks and other individuals, the IRs experienced a large decline before 1985, and then gradually stabilized and increased slightly (Figure $2 A, B$ ). However, the IRs in all races have been increasing for patients with a previous malignancy (Figure $2 C$ ). Additionally, the IRs in black individuals were the highest while those in other races (AI/AN and $\mathrm{A} / \mathrm{PI})$ were the lowest no matter in which population.

The IR trend in the general population was consistent with that in patients without a previous malignancy (Figure 3). Among people with a previous primary cancer, the IR trends varied greatly, which may be explained by a small population base and a small number of cases. On the whole, the IRs were basically on the rise among people of all age groups. As for different age groups, the IRs of PSCC in the general population increased along with age. For those younger than 50 years old, the IRs were very low, especially in people younger than 35 years old (tended to be 0 ).

From 1975 to 2016, the overall IRs of PSCC were on the rise in all populations (Figure 4). For the general population, people without/with previous primary cancer, the APCs were $1.33,0.69$ and 4.32 , respectively (all $\mathrm{P}<0.05$ ).

\section{Survival outcomes}

A total of 6,079 patients were selected for CSS analysis (43 patients were excluded because of unknown cause of death). Multivariate Cox analysis showed that age at diagnosis, pathological grade, extent of disease, marital status, the administration of surgery and presence of previous primary malignancy were independent prognostic factors for CSS (Table 5).

Subsequently, KM curves were generated to learn the actual effect of different variables on CSS (Figure 5). Older patients had worse prognosis than younger patients $(\mathrm{P}<0.001)$. Patients who underwent surgery had better prognosis than those who did not $(\mathrm{P}<0.001)$. Additionally, patients with distant diseases or higher-grade pathology 
Table 1 Demographic characteristics of patients with penile squamous cell carcinoma based on existence of a prior primary from SEER 18

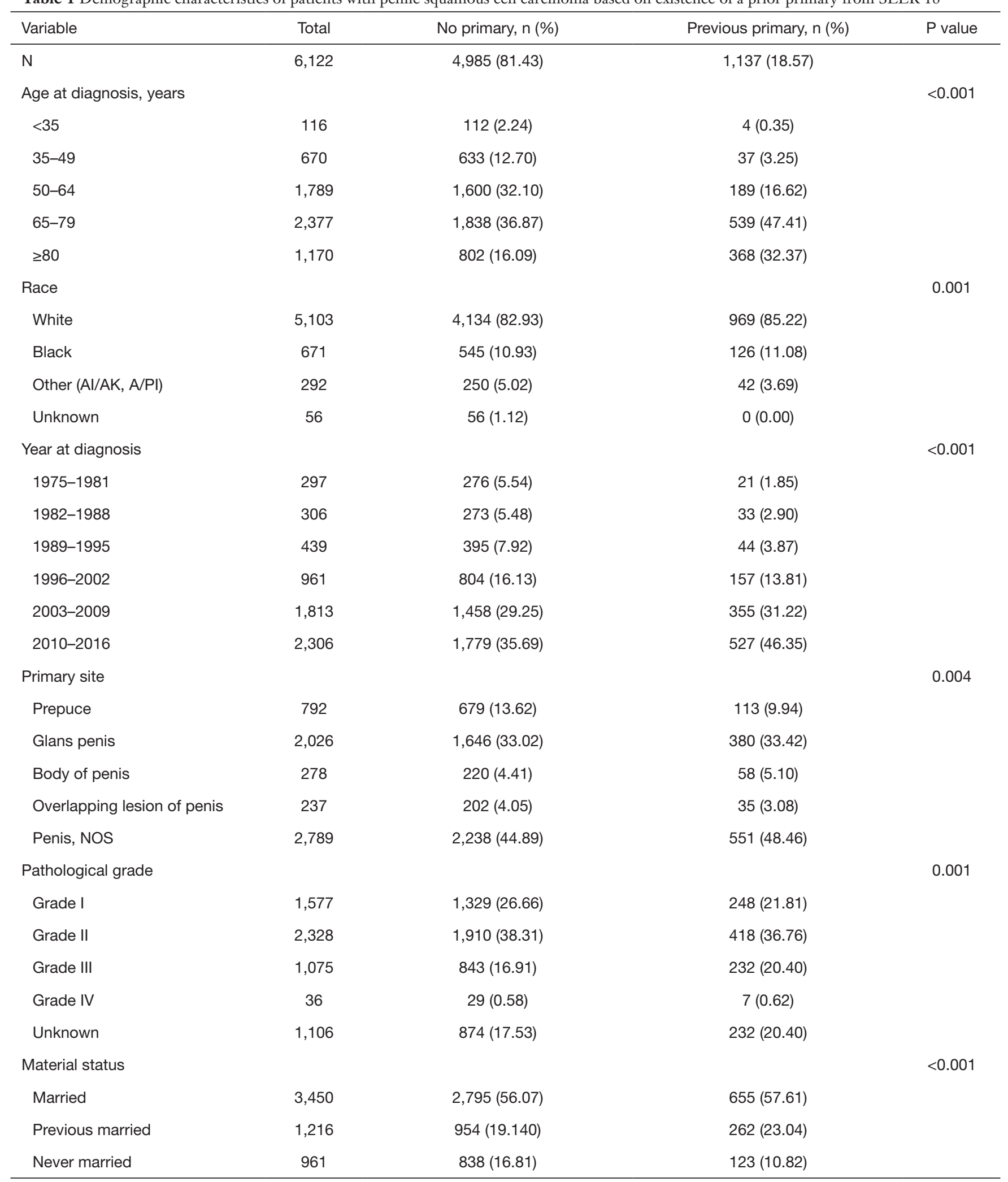

Table 1 (Continued) 
Table 1 (Continued)

\begin{tabular}{lccc}
\hline Variable & Total & No primary, $\mathrm{n}(\%)$ & Previous primary, $\mathrm{n}(\%)$ \\
\hline Unknown & 495 & $398(7.98)$ & $97(8.53)$ \\
Extent of disease & & & 0.033 \\
Localized & 3,519 & $2,847(57.11)$ & $672(59.10)$ \\
Regional & 1,760 & $1,458(29.25)$ & $302(26.56)$ \\
Distant & 298 & $253(5.08)$ & $45.96)$ \\
Unstaged & 545 & $427(8.57)$ & $118(10.38)$ \\
Surgery & & & $243(21.37)$ \\
Unknown/no & 1,614 & $1,371(27.50)$ & $894(78.63)$ \\
Yes & 4,508 & $3,614(72.50)$ & $<0.001$ \\
\hline
\end{tabular}

Grade I, well differentiated; Grade II, moderately differentiated; Grade III, poorly differentiated; Grade IV, undifferentiated; anaplastic.

Table 2 Case counts and incidence rates for penile squamous cell carcinoma by racial group and age group, SEER 9 (1975-1991)

\begin{tabular}{|c|c|c|c|c|c|c|c|c|c|c|c|c|}
\hline & \multicolumn{3}{|c|}{ Total } & \multicolumn{3}{|c|}{ White } & \multicolumn{3}{|c|}{ Black } & \multicolumn{3}{|c|}{ Other } \\
\hline Total & 0.534 & 729 & $183,707,355$ & 0.514 & 604 & $151,716,668$ & 1.070 & 106 & $18,371,455$ & 0.191 & 17 & $13,619,232$ \\
\hline $\begin{array}{l}\text { No } \\
\text { primary }\end{array}$ & 0.479 & 665 & $183,707,355$ & 0.460 & 550 & $151,716,668$ & 0.970 & 97 & $18,371,455$ & 0.182 & 16 & $13,619,232$ \\
\hline \multicolumn{13}{|l|}{ Age group } \\
\hline \multicolumn{13}{|c|}{ No primary } \\
\hline$<35$ & 0.009 & 10 & $108,234,673$ & 0.006 & 6 & $87,299,672$ & 0.009 & 1 & $12,353,899$ & 0.025 & 2 & $8,581,102$ \\
\hline $35-49$ & 0.217 & 71 & $34,138,599$ & 0.204 & 56 & $28,689,163$ & 0.405 & 12 & $3,026,549$ & 0.139 & 3 & $2,422,887$ \\
\hline$\geq 80$ & 2.862 & 80 & $2,832,394$ & 2.789 & 69 & $2,514,753$ & 5.757 & 9 & 153,524 & 1.264 & 2 & 164,117 \\
\hline \multicolumn{13}{|c|}{ Previous primary } \\
\hline$<35$ & 0.001 & 1 & $108,234,673$ & 0.001 & 1 & $87,299,672$ & 0.000 & 0 & $12,353,899$ & 0.000 & 0 & $8,581,102$ \\
\hline $35-49$ & 0.009 & 3 & $34,138,599$ & 0.007 & 2 & $28,689,163$ & 0.038 & 1 & $3,026,549$ & 0.000 & 0 & $2,422,887$ \\
\hline $50-64$ & 0.043 & 11 & $24,849,234$ & 0.037 & 8 & $21,378,640$ & 0.098 & 2 & $1,903,189$ & 0.062 & 1 & $1,567,405$ \\
\hline $65-79$ & 0.201 & 27 & $13,652,455$ & 0.185 & 22 & $11,834,440$ & 0.619 & 5 & 934,294 & 0.000 & 0 & 883,721 \\
\hline$\geq 80$ & 0.807 & 22 & $2,832,394$ & 0.873 & 21 & $2,514,753$ & 0.582 & 1 & 153,524 & 0.000 & 0 & 164,117 \\
\hline
\end{tabular}




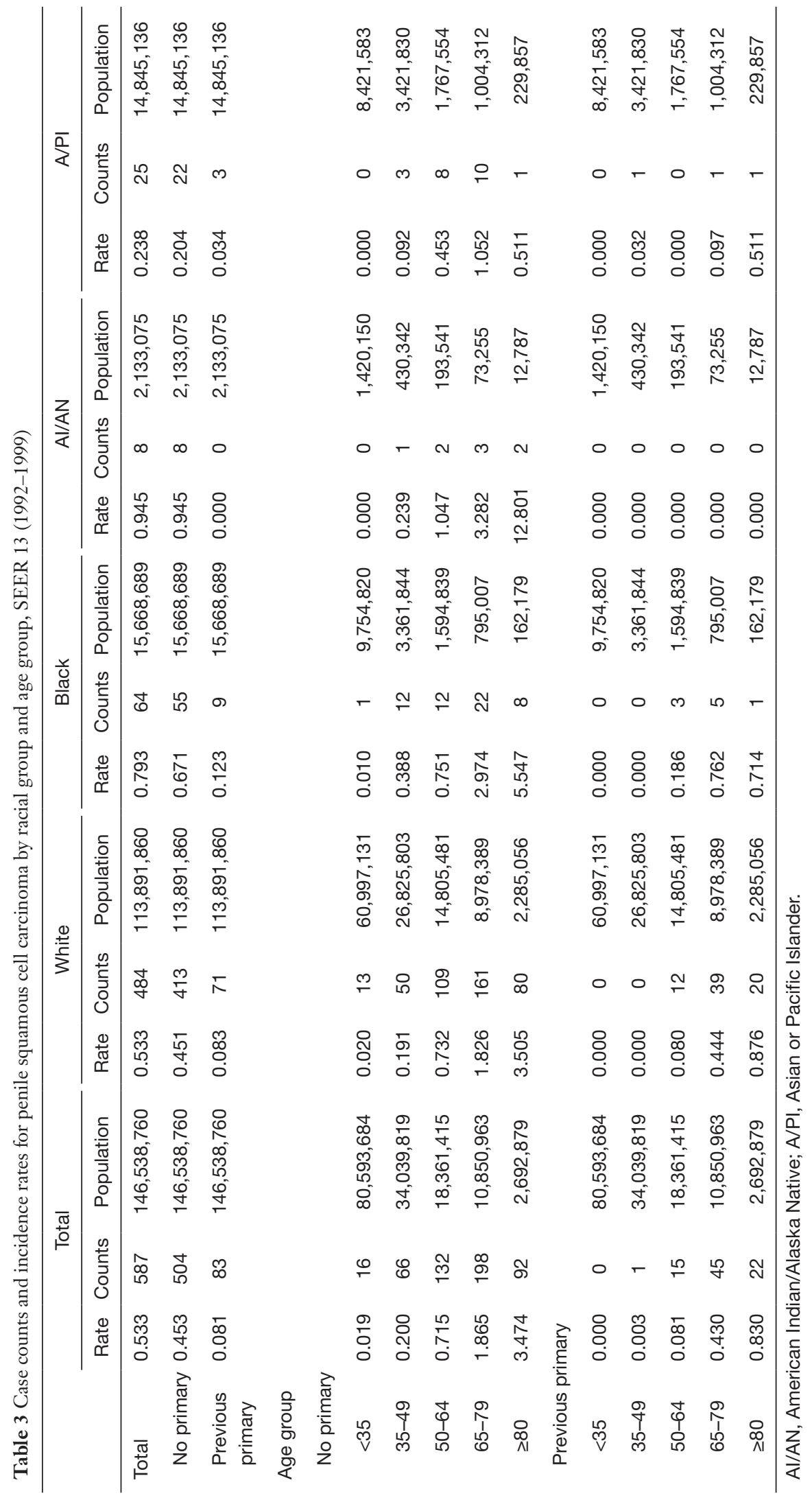




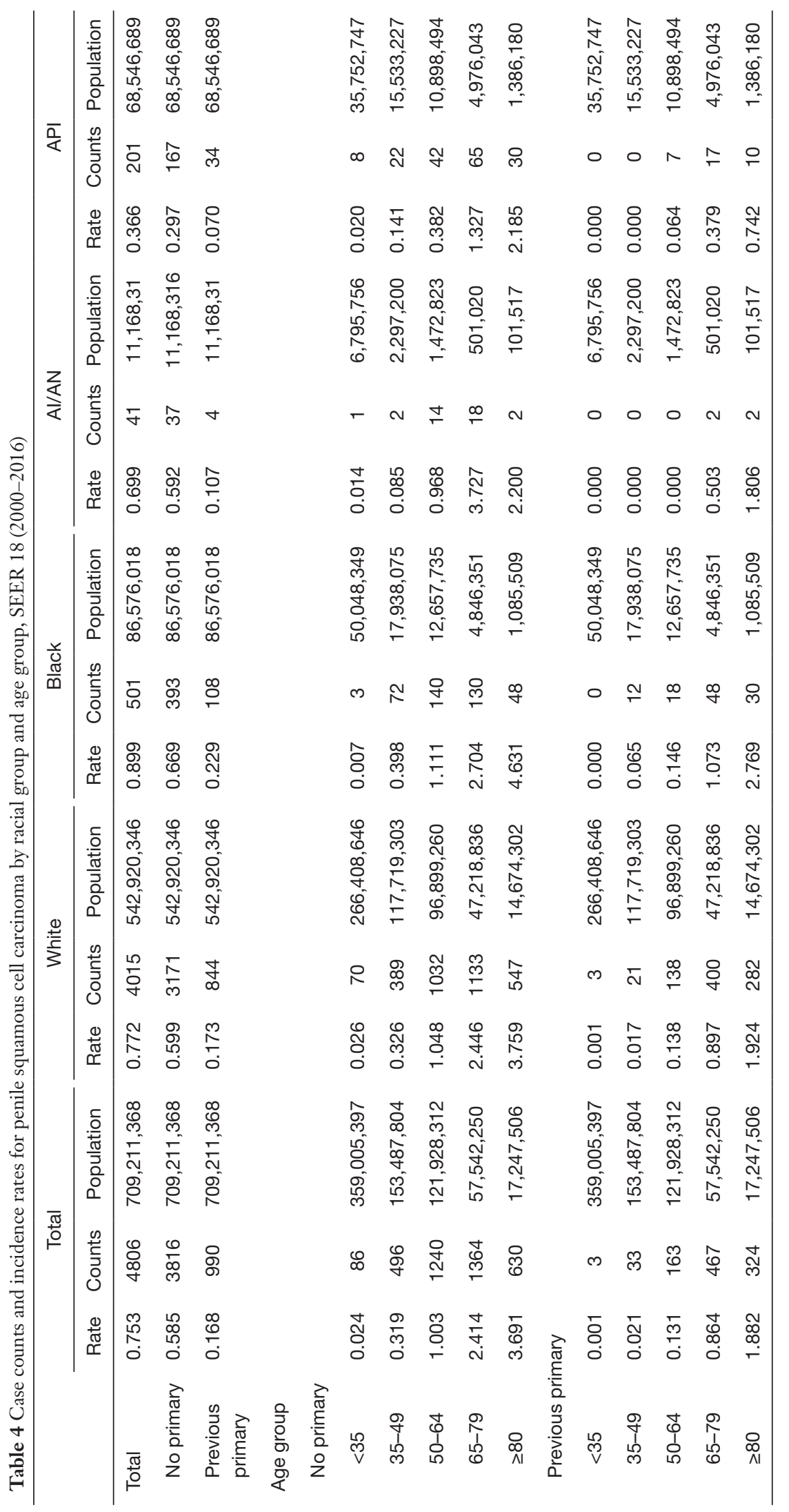




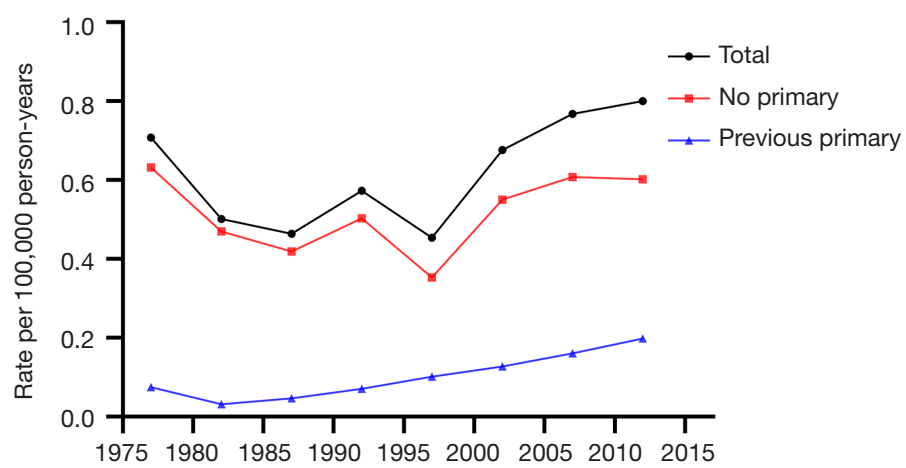

Figure 1 Incidence rates trends of penile squamous cell carcinoma in men from 1975 to 2016.
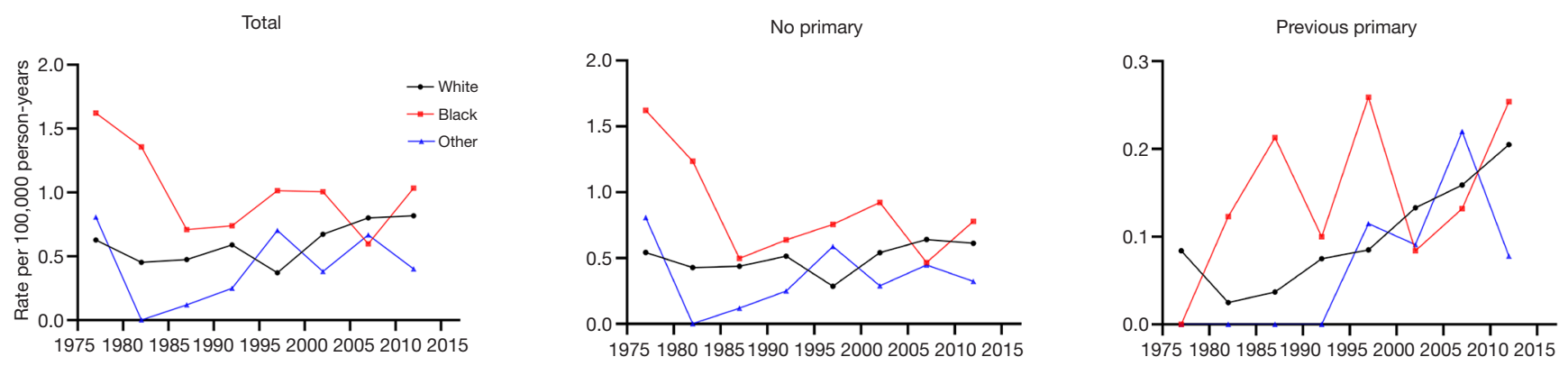

Figure 2 Incidence rates trends of penile squamous cell carcinoma in men by race from 1975 to 2016.

had worse CSS. In our study, the prognosis of married men was relatively better than those who were never married. Interestingly, we found that patients with a previous malignancy had better CSS than those who did not. We believed that many patients would die from the previous cancer, but not PSCC. To verify our conjecture, we analyzed the survival impact of previous malignancies on PSCC patients. Results showed that a previous primary malignancy was tightly associated with worse OS in PSCC patients (Figure 6).

\section{Discussion}

This study provided a view of the epidemiological of PSCC in the USA from 1975 to 2016. IRs of PSCC in this study were similar with those in previously published studies. Research conducted by Barnholtz-Sloan et al. revealed that there were 5.8 new cases of penis cancer per million men per year on average between 1993 and 2002 in the USA (4). Lagacé et al. demonstrated that the IR of penile cancer in Canada was 6.077 per million men per year from 1992 to 2010 (16). This consistency indicated the geographic continuity of incidence trends, since these studies were all based on populations in North America. In our study, the overall IR of PSCC was basically similar to that in previous studies.

An over-time increase in the overall IR of PSCC was identified from 1997 to 2016. Such a growing trend of IR may be attributed to an increasing rate of HPV infection which was widely recognized as a risk factor of PSCC development, as well as a lower rate of neonatal circumcision (17-20). Neonatal circumcision was negatively associated with the risk of PSCC, since it may reduce the risk of HIV and HPV infection and chronic inflammation by eliminating dirt (10). For those without a previous primary malignancy, the IR experienced a decline before 1987, while for those with a previous primary malignancy, the IR has been increasing since 1975. Therefore, difference in incidence may be attributed to the history of malignant tumors, which may transfer to the penis or make the body in a low immune status, thus promoting this upward trend. Moreover, we found that the IRs in black individuals were the highest, which may because of the early exposure to HPV through sexual contact $(4,8,21)$. Furthermore, our 

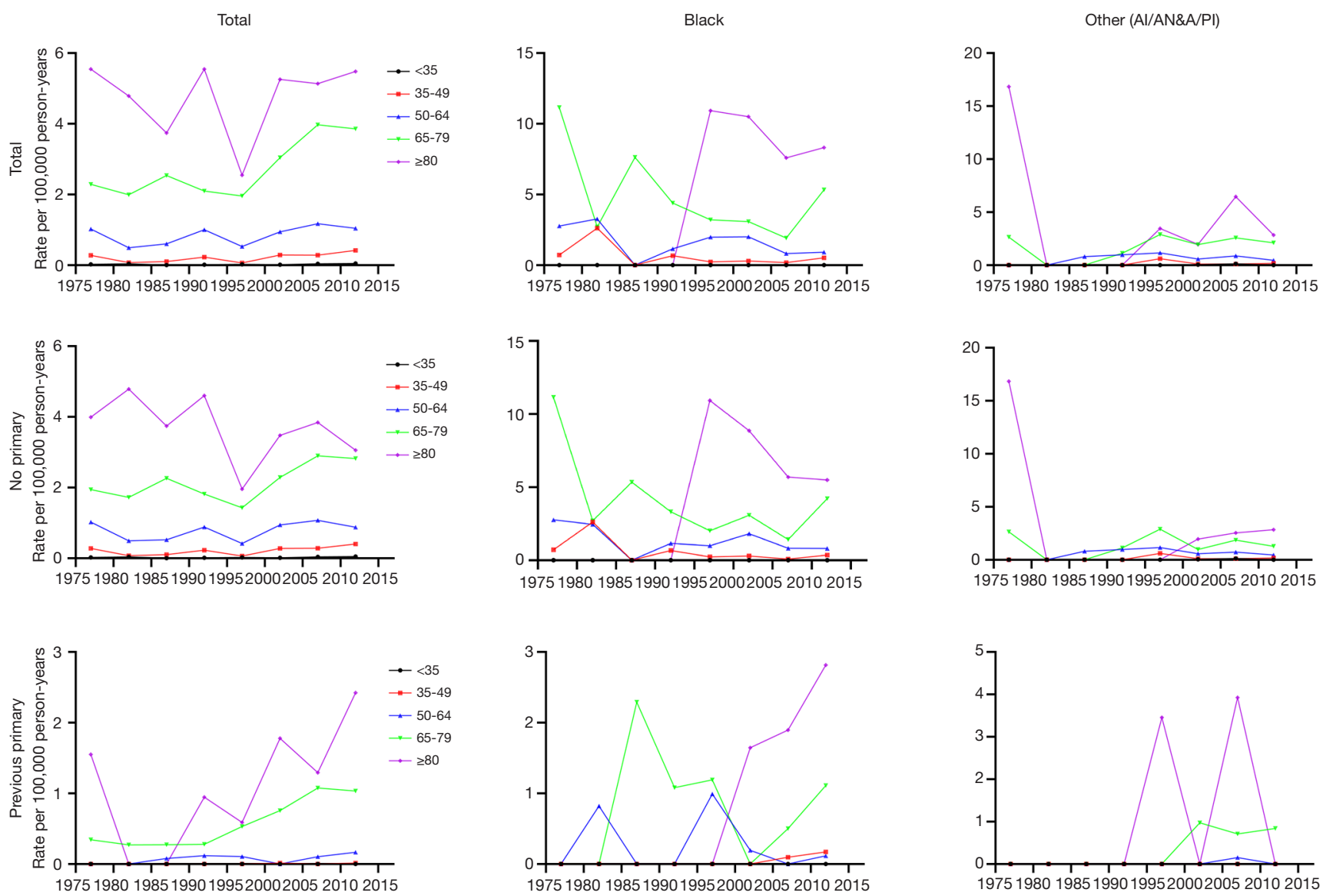

Figure 3 Incidence rates trends of penile squamous cell carcinoma in men by age from 1975 to 2016.

results revealed that the IRs increased along with age, and in people younger than 50 years old, the IRs tended to be zero. Ertoy Baydar et al. reported that the average age of PSCC diagnosis was 66.5 years (51-83 years) in their study (22). This age stratification suggested that older patients, especially those older than 50, were at a higher risk of developing PSCC.

In our study, age at diagnosis, pathological grade, extent of disease, marital status, the administration of surgery and presence of previous primary malignancy were identified to be independent prognostic factors for CSS in PSCC patients. Previous studies have reported that age, tumor stage, extent of disease and the administration of surgery were significantly associated with tumor prognosis in many cancer types $(23,24)$. To our knowledge, those patients who were older, poorly differentiated, metastatic, and not surgically resected were bound to have a poor prognosis. Additionally, Ulff-Møller et al. found that unmarried men were at increased risk of developing invasive penile cancer compared to married men (25). In many Western countries, it has been increasingly common for couples to have unregistered partnerships like marriage. It may be biased to use marital status to evaluate prognosis, since marital status may not directly reflect the number of sexual partners. Furthermore, we found that patients with a history of previous malignancies tended to have a poor prognosis. Firstly, those with a prior primary cancer were more likely to be older, diagnosed in the last decade and had worse differentiation. Additionally, patients with previous malignancies were in worse physical condition and psychological health, which were tightly associated with worse prognosis.

The main advantage of our study was the use of large population-based datasets. However, our research still had some limitations. First of all, numerous large-scale population-based studies have been shown to own inherent limitations, including the risk of data loss and patient classification errors. Sanders et al. (26) discussed these 
A

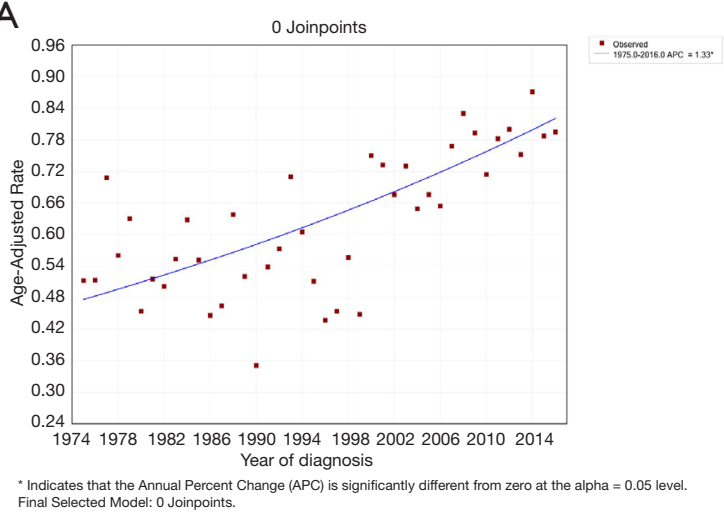

* Indicates that the Annual Percent Change (APC) is significantly different from zero at the alpha $=0.05$ level.

C

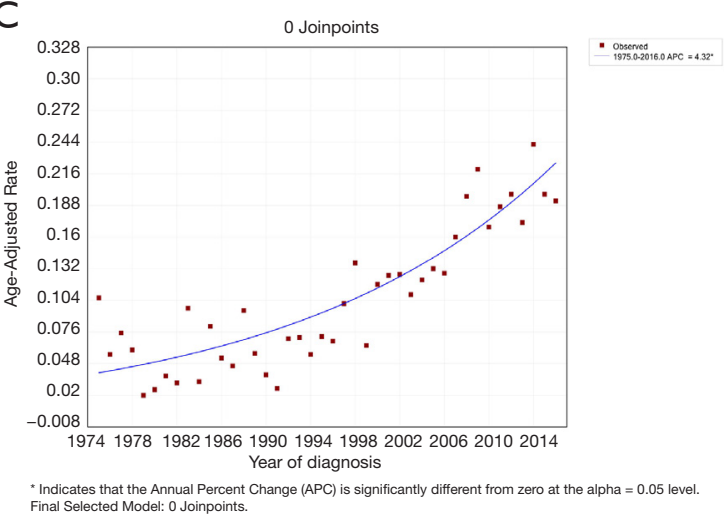

B

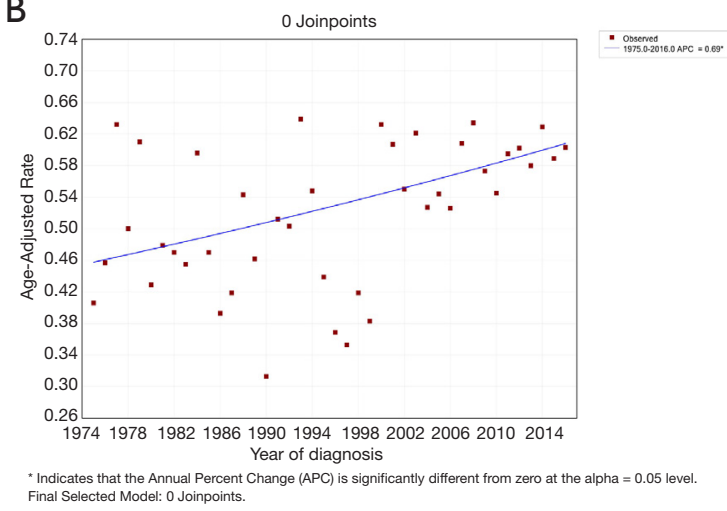

Figure 4 Annual percentage change curves for different populations: the general population (A), people without a primary malignancy (B), people with a primary malignancy $(\mathrm{C})$.

Table 5 Multivariate analysis adjusting for factors affecting the cancer-specific survival

\begin{tabular}{lccc}
\hline Variable & \multicolumn{2}{c}{ Multivariate analysis } & P value \\
\cline { 2 - 4 } & HR & Cl & 0.000 \\
Primary cancer & & Ref & 0.000 \\
No primary & 0.518 & $0.428-0.628$ & 0.000 \\
Previous primary & & Ref & 0.810 \\
Age at diagnosis & & $0.661-1.698$ & 0.668 \\
$<35$ & 1.059 & $0.701-1.742$ & 0.319 \\
$35-49$ & 1.105 & $0.800-1.987$ & 0.003 \\
$50-64$ & 1.260 & $1.282-3.253$ & 0.125 \\
$65-79$ & 3.253 & & Ref \\
Race & & & \\
White & & & \\
\hline
\end{tabular}

Table 5 (Continued) 
Table 5 (Continued)

\begin{tabular}{|c|c|c|c|}
\hline Variable & \multicolumn{3}{|c|}{ Multivariate analysis } \\
\hline Black & 1.034 & $0.871-1.228$ & 0.701 \\
\hline Other (Al/AN, A/PI) & 0.827 & $0.625-1.095$ & 0.185 \\
\hline Unknown & 0.142 & $0.020-1.017$ & 0.052 \\
\hline $1975-1984$ & & Ref & \\
\hline 1985-1994 & 0.929 & $0.725-1.190$ & 0.560 \\
\hline 1995-2004 & 1.132 & $0.878-1.458$ & 0.338 \\
\hline 2005-2016 & 1.275 & $0.985-1.650$ & 0.065 \\
\hline Glans penis & 1.006 & $0.821-1.234$ & 0.951 \\
\hline Body of penis & 1.137 & $0.836-1.544$ & 0.413 \\
\hline Overlapping lesion of penis & 1.463 & $1.078-1.986$ & 0.015 \\
\hline Penis, NOS & 1.070 & $0.878-1.305$ & 0.501 \\
\hline Pathological grade & & & 0.000 \\
\hline Grade I & & Ref & \\
\hline Grade II & 2.015 & $1.704-2.383$ & 0.000 \\
\hline Grade III & 2.316 & $1.923-2.788$ & 0.000 \\
\hline Distant & 10.964 & $9.191-13.080$ & 0.000 \\
\hline Unstaged & 2.254 & $1.711-2.970$ & 0.000 \\
\hline Marital status & & & 0.001 \\
\hline Married & & Ref & \\
\hline Previously married & 1.216 & $1.055-1.403$ & 0.007 \\
\hline Never married & 1.296 & $1.110-1.513$ & 0.001 \\
\hline Unknown & 0.942 & $0.736-1.207$ & 0.637 \\
\hline Surgery & & & 0.000 \\
\hline No/Unknown & & Ref & \\
\hline Yes & 0.551 & $0.464-0.655$ & 0.000 \\
\hline
\end{tabular}



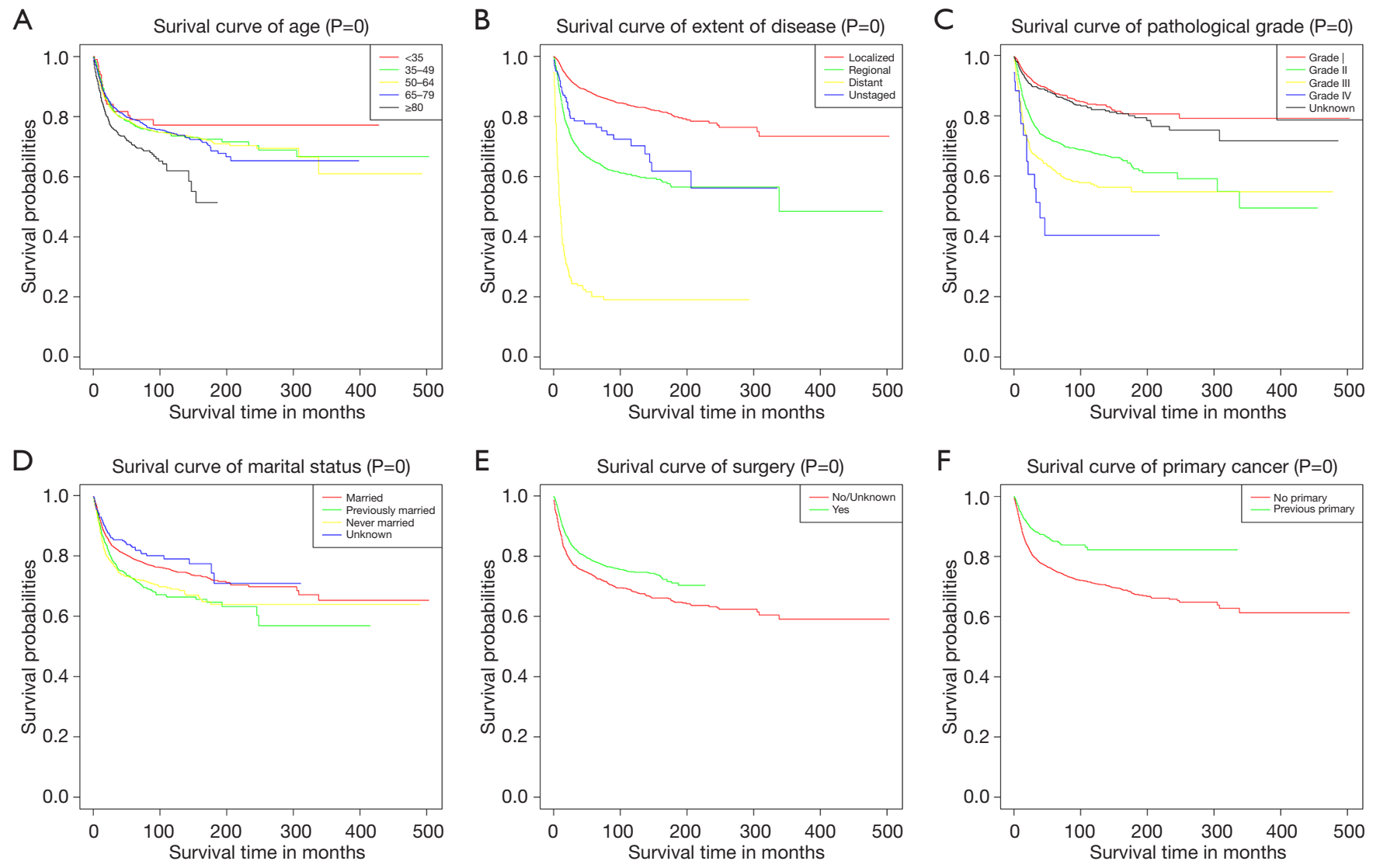

Figure 5 Kaplan-Meier curves of cancer-specific survival stratified by age (A), extent of disease (B), pathological grade (C), marital status (D), use of surgery $(\mathrm{E})$ and presence of a previous primary malignancy $(\mathrm{F})$.

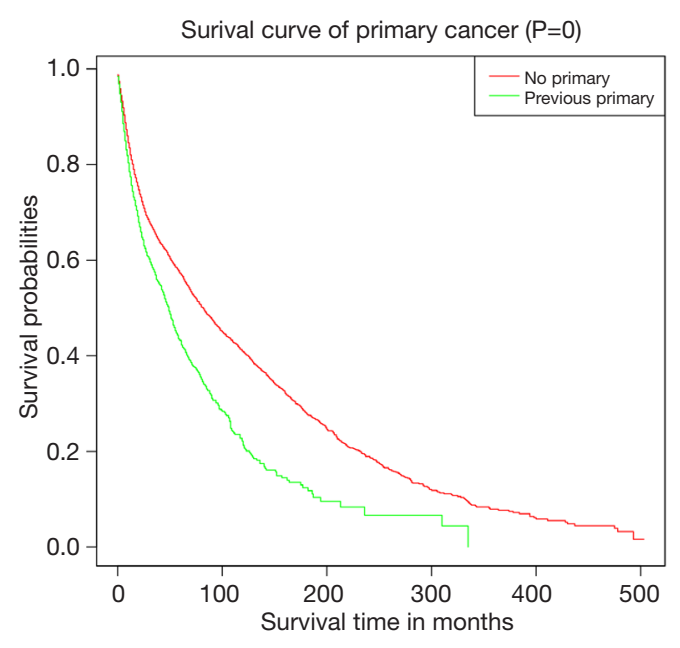

Figure 6 Kaplan-Meier curves of overall survival for stratification by presence of a previous primary malignancy. limitations in more detail in their article. In addition, selection bias may exist because of the retrospective nature. Moreover, there was a deficiency of available data on certain risk factors related to incidence and prognosis in SEER database, such as smoking history, HPV infection status and chemotherapy status, which may affect the comprehensiveness of the conclusions. Hence, further prospective and well-designed studies are needed to validate our results.

In conclusion, our study provided a view of the epidemiological of PSCC in US from 1975 to 2016. The incidence of PSCC has been increasing in recent years. Moreover, several independent prognostic factors for CSS of PSCC patients were identified, allowing surgeons to assess the individualized risk in advance.

\section{Acknowledgments}


Funding: This work was supported by National Natural Science Foundation of China (No.81702520).

\section{Footnote}

Reporting Checklist: The authors have completed the PRISMA reporting checklist. Available at http://dx.doi. org/10.21037/atm-20-1802

Conflicts of Interest: All authors have completed the ICMJE uniform disclosure form (available at http://dx.doi. org/10.21037/atm-20-1802). XL served as an unpaid Section Editor of Annals of Translational Medicine from January 2020 to December 2021. The other authors have no conflicts of interest to declare.

Ethical Statement: The authors are accountable for all aspects of the work in ensuring that questions related to the accuracy or integrity of any part of the work are appropriately investigated and resolved. This study was exempt from Institutional Review Board (IRB) approval because the original data were from a public database.

Open Access Statement: This is an Open Access article distributed in accordance with the Creative Commons Attribution-NonCommercial-NoDerivs 4.0 International License (CC BY-NC-ND 4.0), which permits the noncommercial replication and distribution of the article with the strict proviso that no changes or edits are made and the original work is properly cited (including links to both the formal publication through the relevant DOI and the license). See: https://creativecommons.org/licenses/by-nc-nd/4.0/.

\section{References}

1. Siegel RL, Miller KD, Jemal A. Cancer statistics, 2020. CA Cancer J Clin 2020;70:7-30.

2. Parkin DM, Bray F. Chapter 2: The burden of HPVrelated cancers. Vaccine. 2006;24 Suppl 3:S3/11-S3/25.

3. Owor R. Carcinoma of the penis in Uganda. IARC Sci Publ 1984;(63):493-7.

4. Barnholtz-Sloan JS, Maldonado JL, Pow-sang J, et al. Incidence trends in primary malignant penile cancer. Urol Oncol 2007;25:361-7.

5. Adeyoju AB, Thornhill J, Corr J, et al. Prognostic factors in squamous cell carcinoma of the penis and implications for management. Br J Urol 1997;80:937-9.
6. Dillner J, von Krogh G, Horenblas S, et al. Etiology of squamous cell carcinoma of the penis. Scand J Urol Nephrol Suppl 2000;(205):189-93.

7. Tsen HF, Morgenstern H, Mack T, et al. Risk factors for penile cancer: results of a population-based case-control study in Los Angeles County (United States). Cancer Causes Control 2001;12:267-77.

8. Goodman MT, Hernandez BY, Shvetsov YB. Demographic and pathologic differences in the incidence of invasive penile cancer in the United States, 1995-2003. Cancer Epidemiol Biomarkers Prev 2007;16:1833-9.

9. Madsen BS, van den Brule AJ, Jensen HL, et al. Risk factors for squamous cell carcinoma of the penis-population-based case-control study in Denmark. Cancer Epidemiol Biomarkers Prev 2008;17:2683-91.

10. Douglawi A, Masterson TA. Updates on the epidemiology and risk factors for penile cancer. Transl Androl Urol 2017;6:785-90.

11. Sewell J, Ranasinghe W, De Silva D, et al. Trends in penile cancer: a comparative study between Australia, England and Wales, and the US. Springerplus 2015;4:420.

12. Schlenker B, Schneede P. The Role of Human Papilloma Virus in Penile Cancer Prevention and New Therapeutic Agents. Eur Urol Focus 2019;5:42-5.

13. Seitz AK, Protzel C, Retz M, et al. [Current state of chemotherapy in treatment of advanced penile cancer]. Aktuelle Urol 2014;45:286-92.

14. Eich ML, Del Carmen Rodriguez Pena M, Schwartz L, et al. Morphology, p16, HPV, and outcomes in squamous cell carcinoma of the penis: a multi-institutional study. Hum Pathol 2020;96:79-86.

15. Song L, Wang Y, Weng G. Metastasis in penile corpus cavernosum from esophageal squamous carcinoma after curative resection: a case report. BMC Cancer 2019;19:162.

16. Lagacé F, Ghazawi FM, Le M, et al. Penile Invasive Squamous Cell Carcinoma: Analysis of Incidence, Mortality Trends, and Geographic Distribution in Canada. J Cutan Med Surg 2020;24:124-8.

17. Christodoulidou M, Sahdev V, Houssein S, et al. Epidemiology of penile cancer. Curr Probl Cancer 2015;39:126-36.

18. Chipollini J, Chaing S, Peyton CC, et al. National Trends and Predictors of Locally Advanced Penile Cancer in the United States (1998-2012). Clin Genitourin Cancer 2017. doi: 10.1016/j.clgc.2017.07.031.

19. Griffiths TR, Mellon JK. Human papillomavirus and urological tumours: I. Basic science and role in penile cancer. BJU Int 1999;84:579-86. 
20. Bezerra AL, Lopes A, Santiago GH, et al. Human papillomavirus as a prognostic factor in carcinoma of the penis: analysis of 82 patients treated with amputation and bilateral lymphadenectomy. Cancer 2001;91:2315-21.

21. Hernandez BY, Barnholtz-Sloan J, German RR, et al. Burden of invasive squamous cell carcinoma of the penis in the United States, 1998-2003. Cancer 2008;113:2883-91.

22. Ertoy Baydar D, Akkaya H, Dusmez Apa D, et al. Squamous cell carcinoma of the penis: a clinicopathological study from a population with late circumcision. Rom J Morphol Embryol 2019;60:521-9.

23. Chai X, Sun MY, Jia HY, et al. A prognostic nomogram for overall survival in male breast cancer with histology

Cite this article as: Qi F, Wei X, Zheng Y, Ren X, Li X, Zhao E. Incidence trends and survival outcomes of penile squamous cell carcinoma: evidence from the Surveillance, Epidemiology and End Results population-based data. Ann Transl Med 2020;8(21):1428. doi: 10.21037/atm-20-1802 of infiltrating duct carcinoma after surgery. PeerJ 2019;7:e7837.

24. Yang J, Pan Z, He Y, et al. Competing-risks model for predicting the prognosis of penile cancer based on the SEER database. Cancer Med 2019;8:7881-9.

25. Ulff-Møller CJ, Simonsen J, Frisch M. Marriage, cohabitation and incidence trends of invasive penile squamous cell carcinoma in Denmark 1978-2010. Int J Cancer 2013;133:1173-9.

26. Sanders CM, Saltzstein SL, Schultzel MM, et al. Understanding the limits of large datasets. J Cancer Educ 2012;27:664-9. 